\title{
Crônica 1
}

\section{Perda para o ecumenismo - pastor Zwinglio Mota Dias}

Conselho Nacional de Igrejas Cristãs do Brasil

O mundo ecumênico perdeu, em 19 de novembro de 2021, o pastor Zwinglio Mota Dias, mineiro nascido em 1941, na cidade de Passa Quatro. Graduado em Teologia na Faculdade Evangélica de Buenos Aires, Argentina, e doutor em Teologia pela Universidade de Hamburgo, Alemanha, foi um teólogo reconhecido internacionalmente, pastor da Igreja Presbiteriana Unida (IPU) - igreja-membro Conselho Nacional de Igrejas Cristãs do Brasil (CONIC).

Zwinglio foi conhecido pela coragem e clareza com que sempre se posicionou em seus textos, livros e pregações. Seus livros e seu comprometimento religioso foram fonte de inspiração para muitas pessoas no mundo ecumênico e no diálogo inter-religioso. Sempre soube se colocar com clareza como servo fiel e anunciador do evangelho no mundo social e político.

Em entrevista concedida em 2015 afirmou: "a vivência da fé, especialmente da fé cristã, perdeu sua dimensão essencial que é viver com e para os demais. Essa experiência de compartilhamento da vida que só se alcança na vivência comunitária aos poucos foi desaparecendo. As igrejas pouco a pouco foram perdendo suas características de serem espaços de exercício da solidariedade e da comunhão. Cada vez mais os templos são maiores, congregando multidões de indivíduos isolados uns dos outros que buscam na solidão de suas incertezas um suposto milagre para a solução de seus problemas. O martelete midiático, repetindo em roupagem religiosa os valores do mercado, reforça permanentemente que esta é a única solução. Somente a recuperação da dimensão perdida da comunhão entre as pessoas, o exercício pleno da solidariedade é que permitirá, novamente, uma vivência profunda da verdade de toda fé".

Disponível em: <https://www.conic.org.br/portal/noticias/3941-lamentamos-a-perda-doquerido-amigo-zwinglio-mota-dias $>$. 


\section{Crônica 2}

\section{Nova Zelândia: acordo histórico entre católicos e luteranos sobre batismo} Conselho Nacional de Igrejas Cristãs do Brasil

O acordo sobre o batismo é o primeiro grande objetivo alcançado pelo trabalho da comissão de diálogo católico-luterana naquele país. A comissão tem realizado encontros regulares desde que foi criada pelo bispo luterano Mark Whitfield e pelo cardeal católico John Dew em 2017, como parte dos serviços neozelandeses que marcam a Reforma do cristianismo europeu iniciada em 1517, quando Martinho Lutero publicou suas 95 teses em Wittenberg, na Alemanha.

Intitula-se Batizados juntos em Cristo, a declaração aprovada conjuntamente pelas igrejas católica e luterana da Nova Zelândia (Aotearoa), na Oceania, que reconhece a unidade de seus respectivos batismos. A declaração, assinala o site da Conferência Episcopal da Nova Zelândia, será particularmente útil para as famílias que desejam batizar seus filhos quando um dos pais é luterano e o outro católico.

"Esta declaração honra nosso compromisso de buscar a unidade que nos une, de ser transformados por nosso encontro com o outro e de promover ulteriores expressões de nossa unidade através de nossas igrejas", comentou o cardeal Dew, enquanto o bispo Whitfield disse: "os ritos batismais católicos e luteranos têm muito em comum, e este trabalho é uma oportunidade bem-vinda para aprender com as práticas uns dos outros".

\section{Aprender uns com os outros e falar com uma única voz}

"As igrejas católica e luterana podem aprender uma da outra e falar com uma voz comum sobre questões que preocupam a sociedade moderna, com a convicção de que compartilham um só batismo e uma única fé”, lê-se na declaração, que também reconhece a existência de diferenças entre as duas: "católicos e luteranos afirmam ambos que através do batismo uma pessoa se torna membro da Igreja una, santa, católica e apostólica. Um casal de pais que inclua um cônjuge católico e o outro luterano é encorajado a levar seu filho para o batismo na igreja de sua escolha. Eles podem procurar que ambos os pastores/padres participem do serviço batismal".

"Os cristãos são encorajados a falar sobre ser batizados na Igreja cristã, na fé cristã, ou em Cristo. Eles podem dizer que foram batizados na Igreja católica ou luterana, mas são desencorajados a dizer que foram batizados católicos ou luteranos", lê-se, por fim.

Disponível em: < https://www.conic.org.br/portal/noticias/3928-nova-zelandia-acordo-historicoentre-catolicos-e-luteranos-sobre-batismo>. 


\section{Crônica 3}

\section{Campanha Primavera para a Vida 2021}

Coordenadoria Ecumênica de Serviço

Foi lançada a $21^{\mathrm{a}}$ edição da Campanha Primavera para a Vida. A largada foi dada em um seminário realizado de maneira virtual em de 22 de setembro. Com o tema Buscar a verdade: um compromisso de fé, o encontro contou com participação da jornalista Magali Cunha, da pastora Romi Bencke e da ativista Ana Gualberto, além de diversos membros do movimento ecumênico.

A campanha aborda o caminho da verdade como um princípio cristão que produz paz e justiça e denuncia os danos que a cultura de produzir e difundir fake news (expressão sofisticada para o termo "mentira") tem causado em nossa sociedade, de modo mais particular em comunidades de fé. Por isso, o texto que nos inspira é: "Guarda os teus lábios de falarem enganosamente, quem diz a verdade manifesta a justiça" (Pv 12,17).

A pastora Romi Bencke, secretária-geral do Conselho Nacional de Igrejas Cristãs do Brasil (CONIC), e a ativista Ana Gualberto, coordenadora de Ações com Comunidades Tradicionais de KOINONIA - Presença Ecumênica e Serviço, foram convidadas a falar no evento sobre experiências pessoais em que foram vítimas de notícias falsas, os desdobramentos e consequências desses episódios.

Ana trouxe um exemplo em que KOINONIA foi acusada pelo jornal $O$ Estado de S.Paulo de ser uma instituição de fachada do ex-ministro da Saúde, Alexandre Padilha, e utilizada para lavar dinheiro. O caso aconteceu em 2014. KOINONIA fez diversos pronunciamentos, provou sua idoneidade, inclusive com parecer do Tribunal de Contas da União, que mostrou não haver nenhuma irregularidade na atuação da ONG.

Disponível em: < https://www.cese.org.br/campanha-primavera-para-a-vida-2021-e-lancadacom-amplo-debate-sobre-fake-news-dentro-das-comunidades-de-fe/>. 


\section{Crônica 4}

\section{Lançamento da Rede Ecumênica da Água - Brasil}

Núcleo Ecumênico e Inter-religioso da PUCPR

No dia 22 de julho de 2021, em evento on-line, foi lançada no Brasil a Rede Ecumênica da Água (REDA-Brasil). Trata-se de uma iniciativa que visa promover a reflexão e a ação sobre as águas no Brasil, conscientizando sobre as várias questões que lhe dizem respeito, sejam elas ambientais ou sociais.

\section{Contexto}

Não obstante o fato de o Brasil ter em seu território o maior volume de água doce do planeta, $70 \%$ dos seus rios poluídos com todo tipo de dejetos industriais, domésticos e químicos. Mudanças climáticas e questões sociais afetam diretamente o abastecimento de água boa à população. Projetos econômicos mercantilizam a água em nosso país.

\section{Resposta}

Frente a essa realidade, a REDA-Brasil afirma três princípios fundamentais sobre a água: ela é dom divino e, portanto, gratuita na recepção e com igual gratuidade deve ser distribuída e utilizada; direito humano como algo essencial para a vida das pessoas - e de todas as criaturas que necessitam da água para sobreviver; e bem comum, como pertença a todas as criaturas e também como algo que nos acomuna no planeta. Desse modo, a água tem um "valor múltiplo" e também um "uso múltiplo". E distribuir água com justiça é fazer justiça à vida de toda a criação.

A REDA-Brasil conta com o apoio da Rede Ecumênica da Água, do Conselho Mundial de Igrejas, criada em 2006.

Organizações fundadoras e conselho consultivo

A REDA-Brasil conta com sete organizações fundadoras: Conselho Nacional de Igrejas Cristãs do Brasil (CONIC), Núcleo Ecumênico e Inter-religioso da PUCPR (NEIr), Instituto Oca do Sol, Coordenadoria Ecumênica de Serviço (CESE), Iniciativa das Religiões Unidas (URI), Centro de Estudos e Ação Social (CEAS) e a Ágora/Brasil. São organizações que têm objetivos ecumênicos, socioambientais e inter-religiosos, que visam favorecer a articulação no Brasil das diversas iniciativas sobre a água que estejam sintonizadas com os três princípios da REDA-Brasil.

Para Bianca Daébs, assessora para ecumenismo e diálogo inter-religioso da CESE, apoiar a Rede Ecumênica da Água significa defender o acesso à água como um bem comum, 
natural e coletivo. "A REDA se articula para defender o acesso a água potável e consequentemente a preservação das nascentes, rios, mares, oceanos e os povos e comunidades tradicionais que nutrem seus corpos e espíritos ao tempo que preservam esses mananciais", afirma.

Além das sete organizações fundadoras, a REDA-Brasil conta com o apoio de um conselho consultivo formado por 17 experts em diversas questões ambientais, como mudanças climáticas, fontes e nascentes, florestas, e oceanos, entre outras. Um verdadeiro time disposto a mudar o jogo a favor da justiça das águas.

\section{Mensagem do papa Francisco}

Para a ocasião do lançamento, o papa Francisco enviou uma honrosa mensagem, manifestando o desejo "que todos os que tomam parte do mencionado projeto possam empenhar-se cada vez mais na custódia da criação", como resposta ao "urgente desafio de proteger nossa casa comum".

Em sua mensagem à REDA-Brasil (leia aqui a íntegra), o papa Francisco lembra que para alcançar tal objetivo é preciso "unir toda a família humana na busca de um desenvolvimento sustentável e integral". Ele conclui desejando "abundantes favores celestiais", com a intercessão de Nossa Senhora Aparecida envia uma "bênção apostólica" para quem se integra aos projetos da REDA-Brasil.

A mensagem do papa Francisco foi encaminhada através de dom Manoel João Francisco, presidente da Comissão Episcopal Pastoral para o Ecumenismo e o Diálogo Interreligioso da Conferência Nacional dos Bispos do Brasil. 